\title{
Correction to: Postoperative isolated lower extremity supplementary motor area syndrome: case report and review of the literature
}

\author{
Nardin Samuel $^{1}$ (D) $\cdot$ Brian Hanak ${ }^{1,2} \cdot$ Jerry Ku $^{1} \cdot$ Ali Moghaddamjou $^{1} \cdot$ \\ Francois Mathieu ${ }^{1} \cdot$ Mahendra Moharir $^{3}$ - Michael D. Taylor ${ }^{1,2,4}$
}

Published online: 18 January 2020

(C) Springer-Verlag GmbH Germany, part of Springer Nature 2020

\section{Correction to: Child's Nervous System \\ https://doi.org/10.1007/s00381-019-04362-2}

The original version of this article unfortunately contained an error. The author apologizes for having provided an incorrect name: "Ali Moghadammjou" should be "Ali Moghaddamjou". Given in this article is the correct author name.

The original article has been corrected.

The online version of the original article can be found at https://doi.org/ 10.1007/s00381-019-04362-2

Michael D. Taylor

michael.taylor@sickkids.ca

1 Division of Neurosurgery, Department of Surgery, University of Toronto, Toronto, ON, Canada

2 Division of Neurosurgery, The Hospital for Sick Children, Toronto, ON, Canada

3 Division of Neurology, The Hospital for Sick Children, Toronto, ON, Canada

4 The Hospital for Sick Children, Univeristy of Toronto, Peter Gilgan Centre for Research and Learning (PGCRL), 686 Bay Street,

17.9410-E-West, Toronto, ON M5G 0A4, Canada 